\title{
The Hispanic Community Children's Health Study/Study of Latino Youth (SOL Youth): Design, objectives and procedures
}

\author{
CR Isasi ${ }^{1}$, MR Carnethon ${ }^{2}$, GX Ayala ${ }^{3,4}$, E Arredondo ${ }^{3,4}$, SI Bangdiwala $^{5}$, ML Daviglus $^{2}$, AM \\ Delamater $^{6}$, JH Eckfeldt ${ }^{7}$, K Perreira $^{5}$, JH Himes ${ }^{8}$, RC Kaplan ${ }^{1}$, and L Van Horn ${ }^{2}$ \\ ${ }^{1}$ Department of Epidemiology \& Population Health, Albert Einstein College of Medicine \\ ${ }^{2}$ Department of Preventive Medicine, Feinberg School of Medicine, Northwestern University \\ ${ }^{3}$ Graduate School of Public Health, San Diego State University \\ ${ }^{4}$ Institute for Behavioral \& Community Health, San Diego State University \\ ${ }^{5}$ Collaborative Studies Coordinating Center, Department of Biostatistics, Gillings School of Global \\ Public Health, University of North Carolina at Chapel Hill \\ ${ }^{6}$ Department of Pediatrics, University of Miami Miller School of Medicine \\ ${ }^{7}$ Department of Lab Medicine \& Pathology, University of Minnesota \\ ${ }^{8}$ Division of Epidemiology \& Community Health, University of Minnesota School of Public Health
}

\begin{abstract}
Purpose-This paper describes the design and methodology of the SOL Youth study, a multicenter study of Hispanic/Latino children living in the US.
\end{abstract}

\begin{abstract}
Methods-Participants are children aged 8-16 years whose parents/legal guardians participated in the Hispanic Community Health Study/Study of Latinos (HCHS/SOL), a large communitybased cohort study of Hispanic/Latino adults living in the US.
\end{abstract}

\begin{abstract}
Results-Between 2012 and 2014, 1600 children recruited from 4 field centers (Bronx, Chicago, Miami and San Diego) will undergo a 3.5 hour examination to collect biospecimens, obtain anthropometric measures, blood pressure, fitness level, dietary intake, and physical activity. Psychosocial and environmental characteristics are assessed by questionnaire. Primary study aims are to examine associations of youth's lifestyle behaviors and cardiometabolic risk factors with (1) youth's acculturation and parent-child differences in acculturation; (2) parenting strategies, family behaviors, and parental health behaviors; and (3) youth's psychosocial functioning.
\end{abstract}

Conclusions-SOL Youth will determine the prevalence and distribution of obesity-promoting lifestyle behaviors, cardiometabolic risk profiles and novel biomarkers associated with obesity and insulin resistance. This paper describes the study methodology and considers advantages and limitations of embedding a cohort of children within a well characterized cohort of adults.

\footnotetext{
(c) 2013 Elsevier Inc. All rights reserved.

Corresponding author: Carmen R. Isasi, MD, PhD, Albert Einstein College of Medicine, Dept. Epidemiology and Population Health, 1300 Morris Park Ave, Belfer Bldg \#1308D, Bronx, NY 10461, 718-430-2950 carmen.isasi@einstein.yu.edu.

Publisher's Disclaimer: This is a PDF file of an unedited manuscript that has been accepted for publication. As a service to our customers we are providing this early version of the manuscript. The manuscript will undergo copyediting, typesetting, and review of the resulting proof before it is published in its final citable form. Please note that during the production process errors may be discovered which could affect the content, and all legal disclaimers that apply to the journal pertain.
} 


\section{INTRODUCTION}

Hispanic/Latino children are disproportionally affected by the obesity epidemic ${ }^{1}$ and are at high risk of developing diabetes and other cardiometabolic disorders. Recent national data indicate that obese adolescents have a higher burden of cardiovascular disease (CVD) risk factors compared to normal weight adolescents. ${ }^{2}$ Findings from cohort studies suggest that adverse levels of cardiovascular risk factors measured in childhood track into young adulthood. ${ }^{3-5}$ Furthermore, the prevalence of pre-diabetes in youth has dramatically increased in recent years. ${ }^{2}$ While the number of CVD risk factors increases with category of weight, a substantial proportion of normal weight youth (37\%) have at least one CVD risk factor. Boys are at higher cardiometabolic risk, but the factors associated with this disparity are unknown. ${ }^{2,6,7}$ In addition, the prevalence of metabolic syndrome and its components is high among overweight Hispanic/Latino children. ${ }^{8}$ Thus, Hispanic/Latino children may be at high risk of living with chronic conditions throughout their lifespans. Despite the broad socio-cultural heterogeneity of the Hispanic/Latino population in the U.S., ${ }^{9}$ current knowledge about risk and protective factors is based mostly on studies limited to MexicanAmerican individuals. ${ }^{10}$

The biological, behavioral and environmental factors that place Hispanic/Latino children at risk for cardiometabolic disorders are complex. One factor that may play a unique role in Hispanic/Latino youth is acculturation-a concept that describes the degree of integration to a dominant culture by members of a minority group. Studies suggest that Hispanic/Latino youth born outside of the US have lower risk of obesity as compared with those who are USborn or who moved to the US at a young age. ${ }^{11-14}$ Although acculturation is cited as a risk factor for obesity in Hispanic/Latino adults, this association is less clear in youth. ${ }^{11,12,14,15}$ Variation in findings may be attributable to the limited set of measures used to capture acculturation (many studies rely solely on language preferences or country of birth) or because few studies have simultaneously evaluated the joint influence of parental acculturation and youth acculturation on the health risk profile of youth. Until a comprehensive set of measures are used to capture acculturation in youth and their caregivers, the contribution of acculturation on the established risk factors for cardiometabolic diseases cannot be determined. Lower parental educational achievement and living in poverty have been documented as risk factors for increased cardiometabolic burden in youth. ${ }^{16,17}$ However, the pathways explaining these inequalities are not well understood, as most of the studies in youth do not include comprehensive assessments of behavioral, psychosocial, familial and biological factors. ${ }^{2,16-21}$

The Hispanic Community Children's Health Study/Study of Latino Youth (SOL Youth) was launched in April 2011 as an ancillary study to the Hispanic Community Health Study/Study of Latinos (HCHS/SOL) to address this knowledge gap. By examining the children of participants enrolled in HCHS/SOL, the largest population-based cohort study of Hispanic/ Latino adults living in four regions of the U.S: Bronx, NY, Chicago, Miami, and San Diego, new and unprecedented findings are anticipated. The specific aims of the SOL Youth study are:

1. To investigate the influence of youth acculturation and parent-child differences in acculturation on youth's lifestyle behaviors and cardiometabolic risk profiles;

2. To examine associations of parenting strategies, family behaviors and parent lifestyle behaviors on youth's lifestyle behaviors and cardiometabolic risk profiles; and

3. To investigate the influence of youth's psychosocial functioning on youth's lifestyle behaviors and cardiometabolic risk profiles. 
The objective of this manuscript is to describe the design, sampling methods, and data collection procedures for the SOL Youth study.

\section{MATERIALS AND METHODS}

\section{Study participants}

The population source for the SOL Youth study is a population-based sample of Hispanic households whose adult members are enrolled in the NIH-initiated HCHS/SOL cohort study. HCHS/SOL is a population-based cohort study of 16,415 Latino adults (ages 18-74 years) who were selected using probability sampling from four US cities (Chicago, IL; Miami, FL; Bronx, NY; San Diego, CA). The aims of HCHS/SOL are to identify risk factors associated with cardiovascular disease, and other chronic conditions. Baseline data collection for the HCHS/SOL study was carried out between 2008 and 2011. HCHS/SOL cohort participants are contacted annually to update their event status. Details about the methodology and protocols of HCHS/SOL are published elsewhere. ${ }^{22}$

SOL Youth Eligibility-Children living with at least one parent or legal guardian who participated in HCHS/SOL are eligible for SOL Youth. A biological relationship between the youth and the HCHS/SOL participant is not required. Eligibility further required that the child: (1) lives at least 5 days/week and 9 months/year with the HCHS/SOL parent or legal guardian; (2) age 8 to 16 years at the time of the baseline examination; and (3) has no known serious physical or cognitive comorbidities that would interfere with his/her ability to complete a clinic visit. All eligible children in the household were invited to participate. Our goal is to recruit an equal number of boys and girls, and youth aged $<11$ years vs. $\geq 11$ years. The projected numbers of participants by ancestry of origin is expected to reflect the diversity of the main HCHS/SOL study. Table 1 displays the anticipated distribution of ancestry of origin across field centers.

\section{Recruitment procedures}

Recruiters from each field center mail letters to all HCHS/SOL participants describing the main goals and procedures of the SOL Youth Study and alerting them that a member of the research staff would call shortly to describe the study. The letter also includes a childfriendly informational flier. Recruiters from each field center call HCHS/SOL participants to find out if they have a child within the target age range, verify individual eligibility, and invite participation. Parents/guardians are asked to accompany their children to the visit, provide written consent and to complete additional assessments not included in their HCHS/ SOL examination. If a HCHS/SOL participant has more than one eligible child, all who are qualified are enrolled. The number of children per household is accounted for in analyses.

Visits are scheduled in the morning to enable collection of overnight fasting blood samples. To minimize missed school days, clinical examinations are primarily scheduled on Saturdays and on weekdays when children are not in school. To increase participation rates, clinic appointment letters are mailed and reminder calls are made the day before the scheduled appointment to confirm the visit or reschedule for another day. Because transportation is often a barrier to participation in research in many underserved communities, participants are reimbursed for their transportation expenses. A tracking system documents recruitment progress, monitors enrollment and response rates.

\section{Overview of the clinic examination and measures}

Study participation includes three components: 1) an initial clinical examination lasting up to 3.5 hours; 2) 7-days of wearing a physical activity monitor; and 3) a repeated 24-hour dietary recall to be completed on the telephone. Prior to the clinical examination, parents are 
instructed to have their children fast for at least 10 hours prior to the examination and to wear light clothing and comfortable shoes. Parents are asked to bring all medications currently being taken by their children. Parents are also informed that their own height and weight will be assessed and that they would be asked to complete some questionnaires.

The informed consent process takes place at each field center research clinic according to the guidelines of each site's Institutional Review Board (IRB), by personnel specifically trained in this process. Before the start of any data collection, parents and children provide written consent or assent. Two field centers (Bronx and San Diego) require children older than 12 years old to sign a consent form instead of an assent. Child assent/consent is obtained separately from that of parents. Both the parental informed consent form and the consent form for children over 12 years of age were structured to allow parents and children the opportunity to agree or to refuse to certain components of the examination (e.g., acquiring and storing child's DNA, use of their information in future studies).

The list of study questionnaires administered to youth and their parents is provided in Table 2. We selected questionnaires that would capture the constructs needed to address our primary study aims, including potential confounders or effect modifiers of our hypothesized associations. The majority of questionnaires were selected because they were validated for use in this age group in previous studies. However, when validated questionnaires were not available we assembled individual questions from multiple studies to create our questionnaire. All questionnaires were pilot tested in age-appropriate samples prior to finalizing for administration in the SOL-Youth study. All questionnaires, with the exception of pubertal status, depressive and anxiety symptoms, tobacco and alcohol use in adolescents aged 12 and older, are interviewer administered.

The examination protocol allows some flexibility in the order of administration of study components, and provides the option of completing the examination on a second visit (within a month) if the family could not stay for the full 3.5 hours in a given day. A set of core components (identified in Table 2 by " $\mathrm{C}$ ") was identified to prioritize examination elements that were critical for the study specific aims and staff was cross-trained in the different components of the protocol. These strategies were implemented to optimize local efficiency in staffing and provide the ability to conduct examinations on multiple children (and their parents) concurrently.

The clinical examination includes phlebotomy, anthropometry (Tanita Body Composition Analyzer TBF-300A, wall-mounted stadiometer, Gulick anthropometric tape), seated blood pressure (OMROM HEM-907XL), fitness test (step test), ${ }^{23}$ pubertal stage (Pubertal Development Scale), ${ }^{24}$ and study questionnaires. Youth are also asked to wear an activity monitor for a week (ActiCal, MiniMiter Respironics). Table 3 describes the study components and approximate time required to collect each measurement. Parents also answer questions regarding their child's medical history and medications use.

Anthropometric measures are also obtained from the parents to update the measurements obtained during their HCHS/SOL examination.

At the end of the examination, staff provides the child and parent with instructions on how the child should wear the activity monitor and when to return it. Each child receives at least $\$ 25$ in gift certificates and/or cash as compensation for their time. Parents receive an additional minimum of $\$ 25$ following completion of the second dietary recall and the return of the physical activity monitor. Actual reimbursement amounts were permitted to vary across field centers consistent with PI's experience on previous successful recruitment efforts. Staff mail parents a report of study findings of clinical relevance and a brief interpretation of their child's values based on current pediatric guidelines (weight status, 
blood pressure, glucose, lipids, and depressive symptoms). Each field center maintains a network of social and clinical resources in the community for referring children to appropriate services as needed.

\section{Selection of Measures}

The selection of study measures was guided by a comprehensive theoretical framework informed by Social Cognitive Theory, ${ }^{25,26}$ described in a companion paper by Ayala et. al (submitted to Annals of Epidemiology). Obesity and insulin resistance were selected as the primary outcomes of the study because they are important public health problems in Latino youth. ${ }^{18,27}$ Study variables and their instruments were selected to provide a comprehensive overview of the major determinants of cardio-metabolic risk and included physiological, psychosocial, cultural, familial, and behavioral variables (Table 2). Complete characterization of parents' own risk profile is available from the HCHS/SOL baseline examination. $^{22}$

The study planned to use existing Spanish translations of validated instruments. Instruments that lacked an existing version in Spanish were translated by a certified translator and reviewed by the study's Translation Subcommittee.

\section{Reading centers}

Central Laboratory-The central laboratory is responsible for developing the protocol and training for specimen collection and processing. Blood specimens obtained by venipuncture are processed at the collection site immediately after drawing according to a standardized protocol. Serum, plasma, and packed cells are frozen at $-70^{\circ} \mathrm{C}$ and shipped to the central laboratory on a weekly basis. Components of the laboratory assessment are listed in Table 4. Frozen specimens (serum, plasma, packed cells for DNA isolation) are stored in a repository at the central laboratory for future biomarker measurements.

Nutrition Reading Center-Two 24-hr dietary recalls are obtained from each child, with parental assistance if needed, to assess dietary intake using the Nutrition Data System for Research (NDSR) software developed by the University of Minnesota. The initial recall, conducted in person at the clinic examination, is followed by a second recall, conducted by telephone within a month of the first recall. The nutrition reading center developed the protocols and is responsible for the centralized training, processing and quality control of the dietary data. A comprehensive database of Hispanic foods initially developed for the parent HCHS/SOL study provides a rich set of standardized recipes and food formulations.

\section{Data management, quality assurance/control, and statistical analysis}

The University of North Carolina at Chapel Hill Collaborative Studies Coordinating Center is the study's coordinating center (CC) for SOL Youth and is responsible for the data management and quality assurance procedures for the study. In collaboration with all study sites, the CC developed a comprehensive data capture and management system along with quality control and quality assurance programs to ensure rigorous and high quality data collection and adherence to the study protocols. Data is entered at the sites into a standardized, industry-compliant web-based data management system (DMS) and transmitted to the CC. Results from the Central Laboratory and the Nutrition Reading Center is transferred via the DMS to the CC at regular intervals throughout the study. Timely transmission of data allows study investigators to address laboratory alert values as they become known. The DMS provided each field center the ability to generate a variety of reports pertaining to recruitment, data quality, specimen tracking and completion of results letters. Quality control activities included monitoring protocol adherence by direct observation of selected procedures, audio-taping interviews, and repeatability studies. The 
$\mathrm{CC}$ will also guide the analytical approach, which will include calculating sample weights for estimating prevalence of risk factors and cardiometabolic profile. Generalized estimating equations (GEE) models with compound symmetric working covariance or multilevel models with a random interpret per household will be used to account for within-family correlations that arise from including more than one child per household. ${ }^{28-30}$ Dyadic analyses will also be conducted to examine the reciprocal influence of youth and parental factors on youth cardiometabolic risk profile. ${ }^{31}$

\section{Cohort Retention}

By building upon an ongoing longitudinal cohort study of adults (HCHS/SOL), SOL-Youth is able to cost-effectively recruit participants and will be able to follow participants more effectively compared to studies that are not affiliated with an established adult cohort. Each field center offers a child-friendly atmosphere and pays special attention to the needs of children and parents to enhance the study experience. In collaboration with HCHS/SOL, participants receive quarterly newsletters, which highlight a member of the research team, discuss progress of the study, provid information on a health topic of potential interest to participants, and include a brief insert designed specifically for SOL-Youth. In addition, participants receive birthday and holiday cards from study personnel.

To facilitate follow-up of participants who may have moved or changed phone numbers since the baseline examination, all participants are asked to provide the names and contact information of at least three people who are not members of their household and who would know how to contact them in case they moved. In addition, each participant is provided with a postage paid change-of-address card at the time of their initial visit and a phone number to call to provide updated contact information.

Although the SOL Youth study is currently funded as a cross-sectional study, the study design and operations are intended to facilitate future studies including repeated examinations. The above mentioned cohort retention efforts are expected to yield a high retention and follow-up rate for future examinations. Of the HCHS/SOL adult participants who have now been followed for three years, $90 \%$ have been successfully contacted, and follow-up rates of over $80 \%$ have been obtained in each field center.

\section{Study governance and oversight}

SOL Youth is a collaborative study using a multiple principal investigator (PI) approach. The scientific and operational direction for the study was provided by a Steering Committee made up of the PI's from each of four field centers, the coordinating center and the two reading centers. The Steering Committee is led by a Chair whose appointment rotated annually among PI's from the field centers. The Steering Committee is charged with implementing and overseeing all study policies and procedures. Subcommittees were created with the charge of guiding selection of measures and instruments, and preparing manuals for each procedure, including aspects related to quality assurance/control. All study materials are approved by the Steering Committee by majority vote. The Steering Committee held weekly conference calls during the first year of the study, and bi-weekly thereafter. Inperson meetings take place annually.

Institutional review boards (IRBs) provide human subject-related oversight at each field center. Additionally, the study falls under the oversight of the Observational Studies Monitoring Board (OSMB) for HCHS/SOL study at the federal level, which monitors participant burden, safety, and progress. 


\section{Dissemination plans}

The findings of SOL Youth will have broad scientific interest and immediate public health applicability. A multifaceted approach will be utilized to disseminate study findings to both professional and lay communities that includes presentation in professional and community meetings, publication in peer reviewed journals, and coordination with each university's media relations staff and NIH/NHLBI to provide press releases about main findings for publication in Spanish and English language media and newspaper outlets. Furthermore, the data collected for this study will be included in the main HCHS/SOL study's limited-use database maintained by the $\mathrm{CC}$ and will be made available to the public according to terms agreed to between NHLBI and the SOL Youth study. As part of the HCHS/SOL database, SOL Youth will provide phenotypic and behavioral information for examining a whole range of intergenerational differences in future investigations.

\section{DISCUSSION}

SOL Youth is one of the largest and most comprehensive studies on cardiometabolic health in a diverse sample of Hispanic/Latino children living in four areas of the United States. The study will provide valuable information about cultural, behavioral, and familial influences on risks for obesity and cardiometabolic abnormalities. Because the SOL Youth study is embedded within a longitudinal cohort study of adults, parental behavioral and phenotypic data are integrated with the children's data. This provides an innovative and unique opportunity to document biological and environmental influences on important health outcomes. Because both studies have stored DNA samples, future studies can take full advantage of the rich dataset to address genetic factors and gene-environment interactions. SOL Youth is highly efficient from the perspective of recruitment because participating families have been involved with HCHS/SOL study staff and investigators for a number of years and are in active follow-up.

Notable strengths of SOL-Youth include population-based methods to recruit participants, a multicenter design with four field centers that allows for the recruitment and collection of data from multiple Hispanic/Latino groups; and a comprehensive characterization of both individual youth and parental factors that includes health status, lifestyle behaviors, and psychosocial characteristics. Our approach will allow us to tease apart the complex concept of acculturation and its influence on cardiometabolic risk profile. In addition, collecting similar data from both youth and parents will allow us to conduct dyadic analyses and examine the reciprocal influence of youth and parental factors on youth cardiometabolic risk profile. Another unique contribution of SOL Youth study is comprehensive assessments of both boys and girls. Hispanic/Latino boys are reported to be at high risk of obesity and cardiometabolic risk. ${ }^{2,6,7,32,33}$ However, little is known about the factors associated with this disparity. Information collected in SOL Youth about boy's lifestyle patterns, mental health functioning, and body image perceptions may help elucidate this issue. Lastly, the inclusion of novel biomarkers (e.g. biomarkers of endothelial function) shown to increase the risk of diabetes and cardiovascular disease in adults will help us understand better the natural history of these associations by examining the role of obesity and metabolic syndrome on these biomarkers in a younger population.

Despite all these advantages, the study is not free of limitations. The most important is that HCHS/SOL was designed to oversample people 45 years and older and under sample those between 18 and 44 years of age. Thus, HCHS/SOL participants are less likely to have younger children in their household than would an unselected group of Hispanic adults. While this may present a limitation for generating prevalence estimates for health behaviors and cardiometabolic risk factors in the sample, we are applying the sample weights generated from the parent study to any estimates of prevalence. Furthermore, we do not feel 
that the sampling strategy presents a limitation in the interpretation of our hypothesis testing on the association of acculturation, psychosocial factors and family functioning with cardiometabolic risk factors. The estimates of effect that we generate should be internally valid and there is no reason to assume that the external validity of the relationships between factors would be compromised based on the selected age distribution. HCHS/SOL was conducted in areas with high Hispanic/Latino concentration, thus, the sample does not capture rural or suburban areas or areas where Latinos are a small minority. Household rosters collected for families participating in in the HCHS/SOL adult cohort did not record the exact ages of children living in the households. Thus, recruitment efforts are time consuming, as we had limited prior knowledge of which households contained children in the target age range, but participation rates are expected to be higher than traditional community-based samples. SOL Youth is currently a cross-sectional study that does not permit us to study how risk factors are associated with changes in body weight and cardiometabolic disease over time. In anticipation of seeking funding for a follow-up study, we have implemented cohort-retention procedures that will allow future examination of longitudinal associations. Additional contributions to the scientific community are anticipated in SOL Youth, as a resource for future ancillary studies that could use measured phenotypes, behaviors, and stored specimens to answer new scientific questions that may emerge in the field.

\section{Conclusions}

Embedding a youth study within an existing adult cohort has numerous logistic and scientific advantages as described in this paper. This approach uses an existing infrastructure that decreases the costs of enrollment and retention efforts while providing a unique opportunity to examine the influence of multiple parental and familial factors on youth cardiometabolic risk profile. SOL Youth is designed to provide a comprehensive characterization of the cardiometabolic health of Latino youth, and will help gain a better understanding of risk and protective factors associated with cardiometabolic risk. Findings from SOL Youth will have public health relevance, guiding the tailoring of cardiovascular health promoting interventions in this population.

\section{Acknowledgments}

The SOL Youth Study was supported by Grant Number R01HL102130 from the National Heart, Lung, And Blood Institute. The children in SOL Youth are drawn from the study of adults: The Hispanic Community Health Study/ Study of Latinos, which was supported by contracts from the National Heart, Lung, and Blood Institute (NHLBI) to the University of North Carolina (N01-HC65233), University of Miami (N01-HC65234), Albert Einstein College of Medicine (N01-HC65235), Northwestern University (N01-HC65236), and San Diego State University (N01HC65237). The following Institutes/Centers/Offices contribute to the HCHS/SOL through a transfer of funds to the NHLBI: National Center on Minority Health and Health Disparities, the National Institute of Deafness and Other Communications Disorders, the National Institute of Dental and Craniofacial Research, the National Institute of Diabetes and Digestive and Kidney Diseases, the National Institute of Neurological Disorders and Stroke, and the Office of Dietary Supplements. The content is solely the responsibility of the authors and does not necessarily represent the official views of the National Heart, Lung, And Blood Institute or the National Institutes of Health.

\section{References}

1. Ogden CL, Carroll MD, Kit BK, Flegal KM. Prevalence of obesity in the United States, 2009-2010. NCHS data brief. Jan.2012 (82):1-8.

2. May AL, Kuklina EV, Yoon PW. Prevalence of cardiovascular disease risk factors among US adolescents, 1999-2008. Pediatrics. Jun; 2012 129(6):1035-1041. [PubMed: 22614778]

3. Freedman DS, Khan LK, Serdula MK, Dietz WH, Srinivasan SR, Berenson GS. The Relation of Childhood BMI to Adult Adiposity: The Bogalusa Heart Study. Pediatrics. Jan 1; 2005 115(1):2227. [PubMed: 15629977] 
4. Whitaker RC, Wright JA, Pepe MS, Seidel KD, Dietz WH. Predicting obesity in young adulthood from childhood and parental obesity. N Engl J Med. Sep 25; 1997 337(13):869-873. [PubMed: 9302300]

5. Juhola J, Magnussen CG, Viikari JS, et al. Tracking of serum lipid levels, blood pressure, and body mass index from childhood to adulthood: the Cardiovascular Risk in Young Finns Study. The Journal of pediatrics. Oct; 2011 159(4):584-590. [PubMed: 21514597]

6. Li C, Ford ES, Zhao G, Mokdad AH. Prevalence of pre-diabetes and its association with clustering of cardiometabolic risk factors and hyperinsulinemia among U.S. adolescents: National Health and Nutrition Examination Survey 2005-2006. Diabetes Care. Feb; 2009 32(2):342-347. [PubMed: 18957533]

7. Marcus MD, Foster GD, El Ghormli L, et al. Shifts in BMI category and associated cardiometabolic risk: prospective results from HEALTHY study. Pediatrics. Apr; 2012 129(4):e983-991. [PubMed: 22430457]

8. Cruz ML, Goran MI. The metabolic syndrome in children and adolescents. Curr Diab Rep. Feb; 2004 4(1):53-62. [PubMed: 14764281]

9. The Pew Hispanic Center. Pew Research Center Report. 2012. The 10 Largest Hispanic Origin Groups: Characteristics, Rankings, Top Counties.

10. Escarce, JJ.; Morales, LS.; Rumbaut, RG. The Health Status and Health Behaviors of Hispanics. In: Tienda, M.; Mitchell, F., editors. National Research Council (US) Panel on Hispanics in the United States. Hispanics and the Future of America. Washington, DC: National Academies Press; 2006.

11. Ahn MK, Juon HS, Gittelsohn J. Association of race/ethnicity, socioeconomic status, acculturation, and environmental factors with risk of overweight among adolescents in California, 2003. Prev Chronic Dis. Jul.2008 5(3):A75. [PubMed: 18558025]

12. Gordon-Larsen P, Harris KM, Ward DS, Popkin BM. Acculturation and overweight-related behaviors among Hispanic immigrants to the US: the National Longitudinal Study of Adolescent Health. Soc Sci Med. Dec; 2003 57(11):2023-2034. [PubMed: 14512234]

13. Popkin BM, Udry JR. Adolescent obesity increases significantly in second and third generation U.S. immigrants: the National Longitudinal Study of Adolescent Health. J Nutr. Apr; 1998 128(4): 701-706. [PubMed: 9521631]

14. Liu JH, Chu YH, Frongillo EA, Probst JC. Generation and acculturation status are associated with dietary intake and body weight in Mexican American adolescents. J Nutr. Feb; 2012 142(2):298305. [PubMed: 22223572]

15. Buttenheim AM, Pebley AR, Hsih K, Chung CY, Goldman N. The shape of things to come? Obesity prevalence among foreign-born vs. US-born Mexican youth in California. Soc Sci Med. Feb.2013 78:1-8. [PubMed: 23273875]

16. Goodman E, McEwen BS, Huang B, Dolan LM, Adler NE. Social inequalities in biomarkers of cardiovascular risk in adolescence. Psychosom Med. Jan-Feb;2005 67(1):9-15. [PubMed: 15673618]

17. Kakinami L, Seguin L, Lambert M, Gauvin L, Nikiema B, Paradis G. Comparison of three lifecourse models of poverty in predicting cardiovascular disease risk in youth. Ann Epidemiol. Aug; 2013 23(8):485-491. [PubMed: 23830840]

18. Ogden CL, Carroll MD, Kit BK, Flegal KM. Prevalence of obesity and trends in body mass index among US children and adolescents, 1999-2010. JAMA. Feb 1; 2012 307(5):483-490. [PubMed: 22253364]

19. Kimm SY, Obarzanek E, Barton BA, et al. Race, socioeconomic status, and obesity in 9- to 10year-old girls: the NHLBI Growth and Health Study. Ann Epidemiol. Jul; 1996 6(4):266-275. [PubMed: 8876836]

20. Schuster MA, Elliott MN, Kanouse DE, et al. Racial and ethnic health disparities among fifthgraders in three cities. N Engl J Med. Aug 23; 2012 367(8):735-745. [PubMed: 22913683]

21. Dwyer T, Sun C, Magnussen CG, et al. Cohort Profile: the international childhood cardiovascular cohort (i3C) consortium. Int J Epidemiol. Feb; 2013 42(1):86-96. [PubMed: 22434861] 
22. Sorlie PD, Avilés-Santa LM, Wassertheil-Smoller S, et al. Design and Implementation of the Hispanic Community Health Study/Study of Latinos. Annals of Epidemiology. 2010; 20(8):629_ 641. [PubMed: 20609343]

23. Francis K, Feinstein R. A simple height-specific and rate-specific step test for children. Southern medical journal. Feb; 1991 84(2):169-174. [PubMed: 1990447]

24. Petersen A, Crocket L, Richards M, Boxer A. A self-reported measure of pubertal status: reliability, validity, and initial norms. Journal of Youth and Adolescence. 1988; 17:117-133. [PubMed: 24277579]

25. Bandura, A. Social foundations of thought and action. A social congitive theory. Englewood Cliffs, NJ: Prentice-Hall, Inc; 1986.

26. Baranowski, T.; Perry, CL.; Parcel, GS. How individuals, entironments and health beahvior interact: Social Cognitive Theory. In: Glanz, K., editor. Health Behavior and Health Education. 3. San Francisco, CA: Jossey-Bass; 2002.

27. Flores G, Fuentes-Afflick E, Barbot O, et al. The health of Latino children: urgent priorities, unanswered questions, and a research agenda. JAMA. Jul 3; 2002 288(1):82-90. [PubMed: 12090866]

28. Vittinghoff, E.; Glidden, DV.; Shiboski, S.; McCulloch, CE. Regression Methods in Biostatistics. New York, NY: Springer; 2005.

29. Diggle, PJ.; Heagerty, P.; Liang, KY.; Zeger, SL. Analysis of Longitudinal Data. Oxford, UK: Oxford University Press; 2013.

30. Rabe-Hesketh, S.; Skrondal, A. Multilevel and Longitudinal Modeling Usig Stata. College Station, TX: Stata Press; 2012.

31. Kenny, DA.; Kashy, DA.; Cook, W. The analysis of dyadic data. New York, NY: Guildford Press; 2006.

32. Batey LS, Goff DC Jr, Tortolero SR, et al. Summary measures of the insulin resistance syndrome are adverse among Mexican-American versus non-Hispanic white children: the Corpus Christi Child Heart Study. Circulation. Dec 16; 1997 96(12):4319-4325. [PubMed: 9416899]

33. Johnson WD, Kroon JJ, Greenway FL, Bouchard C, Ryan D, Katzmarzyk PT. Prevalence of risk factors for metabolic syndrome in adolescents: National Health and Nutrition Examination Survey (NHANES), 2001-2006. Arch Pediatr Adolesc Med. Apr; 2009 163(4):371-377. [PubMed: 19349567]

34. HCHS/SOL. [Accessed 8/06/2013, 2013] Public Manuals and Documents. http:// www.cscc.unc.edu/hchs/public/docfilter.php?study=hchs\&filter_type=public

35. The National Longitudinal Study of Adolescent Health (Add Health).

36. Andaya A, Arredondo E, Alcaraz J, Lindsay S, Elder J. The association between family meals, TV viewing during meals, and fruit, vegetables, soda, and chips intake among Latino children. J Nutr Educ Behav. Oct.2010

37. Ayala G, Rogers M, Arredondo E, et al. Away-from-home food intake and risk for obesity: examining the influence of context. Obesity (Silver Spring). May; 2008 16(5):1002-1008. [PubMed: 18309297]

38. Emond JA, Madanat HN, Ayala GX. Do Latino and non-Latino grocery stores differ in the availability and affordability of healthy food items in a low-income, metropolitan region? Public health nutrition. Feb; 2012 15(2):360-369. [PubMed: 21733278]

39. Pierce JP, Choi WS, Gilpin EA, Farkas AJ, Merritt RK. Validation of susceptibility as a predictor of which adolescents take up smoking in the United States. Health Psychol. Sep; 1996 15(5):355361. [PubMed: 8891714]

40. Elder JP, Campbell NR, Litrownik AJ, et al. Predictors of cigarette and alcohol susceptibility and use among Hispanic migrant adolescents. Preventive medicine. Aug; 2000 31(2 Pt 1):115-123. [PubMed: 10938211]

41. Wolfson AR, Carskadon MA, Acebo C, et al. Evidence for the validity of a sleep habits survey for adolescents. Sleep. Mar 15; 2003 26(2):213-216. [PubMed: 12683482]

42. Esliger DW, Tremblay MS. Technical reliability assessment of three accelerometer models in a mechanical setup. Med Sci Sports Exerc. Dec; 2006 38(12):2173-2181. [PubMed: 17146326] 
43. McMurray RG, Ring KB, Treuth MS, et al. Comparison of two approaches to structured physical activity surveys for adolescents. Med Sci Sports Exerc. Dec; 2004 36(12):2135-2143. [PubMed: 15570151]

44. Marín G, Gamba RJ. A new measurement of acculturation for Hispanics: the Bidimensional Acculturation Scale for Hispanics (BAS). Hispanic J Behav Sci. Aug; 1996 18(3):297-316.

45. Unger JB, Gallahen P, Shakib S, Ritt-Olson A, Palmer PH, Johnson CA. The AHIMSA Acculturation Scale: a new measure of acculturation for adolescents in a multicultural society. $\mathrm{J}$ Early Adolescence. 2002; 22(3):225-251.

46. Phinney JS. The Multigroup Ethnic Identity Measure: a new scale for use with diverse groups. J Adolescent Res. 1992; 7(2):156-176.

47. Gil AG, Vega WA, Dimas JM. Acculturative stress and personal adjustment among Hispanic adolescent boys. J Community Psychol. 1994; 22(1):43-54.

48. National Health and Nutrition Examination Survey. Centers for Disease Control and Prevention; http://www.cdc.gov/nchs/nhanes/nhanes_questionnaires.htm

49. Jackson C, Henriksen L, Foshee VA. The Authoritative Parenting Index: predicting health risk behaviors among children and adolescents. Health Educ Behav. Jun; 1998 25(3):319-337. [PubMed: 9615242]

50. Larios S, Ayala G, Arredondo E, Baquero B, Elder J. Development and validation of a scale to measure Latino parenting strategies related to children's obesigenic behaviors. The parenting strategies for eating and activity scale (PEAS). Appetite. Feb; 2009 52(1):166-172. [PubMed: 18845197]

51. Norman GJ, Carlson JA, Sallis JF, Wagner N, Calfas KJ, Patrick K. Reliability and validity of brief psychosocial measures related to dietary behaviors. Int J Behav Nutr Phys Act. 2010; 7:56. [PubMed: 20594360]

52. Norman GJ, Sallis JF, Gaskins R. Comparability and reliability of paper- and computer-based measures of psychosocial constructs for adolescent physical activity and sedentary behaviors. Res Q Exerc Sport. Sep; 2005 76(3):315-323. [PubMed: 16270708]

53. Tandon PS, Zhou C, Sallis JF, Cain KL, Frank LD, Saelens BE. Home environment relationships with children's physical activity, sedentary time, and screen time by socioeconomic status. Int J Behav Nutr Phys Act. 2012; 9:88. [PubMed: 22835155]

54. Rosenberg DE, Sallis JF, Kerr J, et al. Brief scales to assess physical activity and sedentary equipment in the home. Int J Behav Nutr Phys Act. 2010; 7:10. [PubMed: 20181057]

55. Aarons GA, McDonald EJ, Connelly CD, Newton RR. Assessment of family functioning in Caucasian and Hispanic Americans: reliability, validity, and factor structure of the Family Assessment Device. Fam Process. Dec; 2007 46(4):557-569. [PubMed: 18092586]

56. Kapinus CA, Corman BK. Closeness with parents and perceived consequences of pregnancy among male and female adolescents. Sociol Quart. 2004; 45(4):691-717.

57. Steidel AGL, Contreras JM. A new familism scale for use with Latino populations. Hispanic J Behav Sci. 2003; 25(3):312-330.

58. Ayala GX, Baquero B, Arredondo EM, Campbell N, Larios S, Elder JP. Association between family variables and Mexican American children's dietary behaviors. J Nutr Educ Behav. MarApr;2007 39(2):62-69. [PubMed: 17346653]

59. Bickel, G.; Nord, M.; Price, C.; Hamilton, W.; Cook, J. United States Department of Agriculture. Guide to Measuring Household Food Security. 2000. Measuring Food Security in the United States.

60. Kovacs, M. Children's depression inventory. Toronto Ontario ; New York: Multi-Health Systems Inc; 1992.

61. March JS, Parker JD, Sullivan K, Stallings P, Conners CK. The Multidimensional Anxiety Scale for Children (MASC): factor structure, reliability, and validity. J Am Acad Child Adolesc Psychiatry. Apr; 1997 36(4):554-565. [PubMed: 9100431]

62. Ayala GX, Mickens L, Galindo P, Elder JP. Acculturation and body image perception among Latino youth. Ethn Health. Jan; 2007 12(1):21-41. [PubMed: 17132583]

63. Heinberg LJ, Thompson JK, Stormer S. Development and validation of the Sociocultural Attitudes Towards Appearance Questionnaire. Int J Eat Disord. Jan; 1995 17(1):81-89. [PubMed: 7894457] 
64. Sallis JF, Grossman RM, Pinski RB, Patterson TL, Nader PR. The development of scales to measure social support for diet and exercise behaviors. Preventive medicine. Nov; 1987 16(6): 825-836. [PubMed: 3432232]

65. Carlson, JA.; Sallis, JF. [Accessed 8/7/2013] Active Where? Individual item reliability statistics adolescent survey. http://www.drjamessallis.sdsu.edu/Documents/ AW_item_reliability_Adolescent.pdf

66. Durant N, Harris SK, Doyle S, et al. Relation of school environment and policy to adolescent physical activity. J Sch Health. Apr; 2009 79(4):153-159. quiz 205-156. [PubMed: 19292847]

67. Portes, A.; Riumbaut, RG. Data Collection Instruments. Children of Imigrants Longitudinal Study (CILS) 1991-2006. ICPR 20520

68. Ayala GX, Elder JP, Campbell NR, et al. Correlates of body mass index and waist-to-hip ratio among Mexican women in the United States: implications for intervention development. Womens Health Issues. Sep-Oct;2004 14(5):155-164. [PubMed: 15482966]

69. Tappe KA, Glanz K, Sallis JF, Zhou C, Saelens BE. Children's physical activity and parents' perception of the neighborhood environment: neighborhood impact on kids study. Int J Behav Nutr Phys Act. 2013; 10:39. [PubMed: 23531282] 


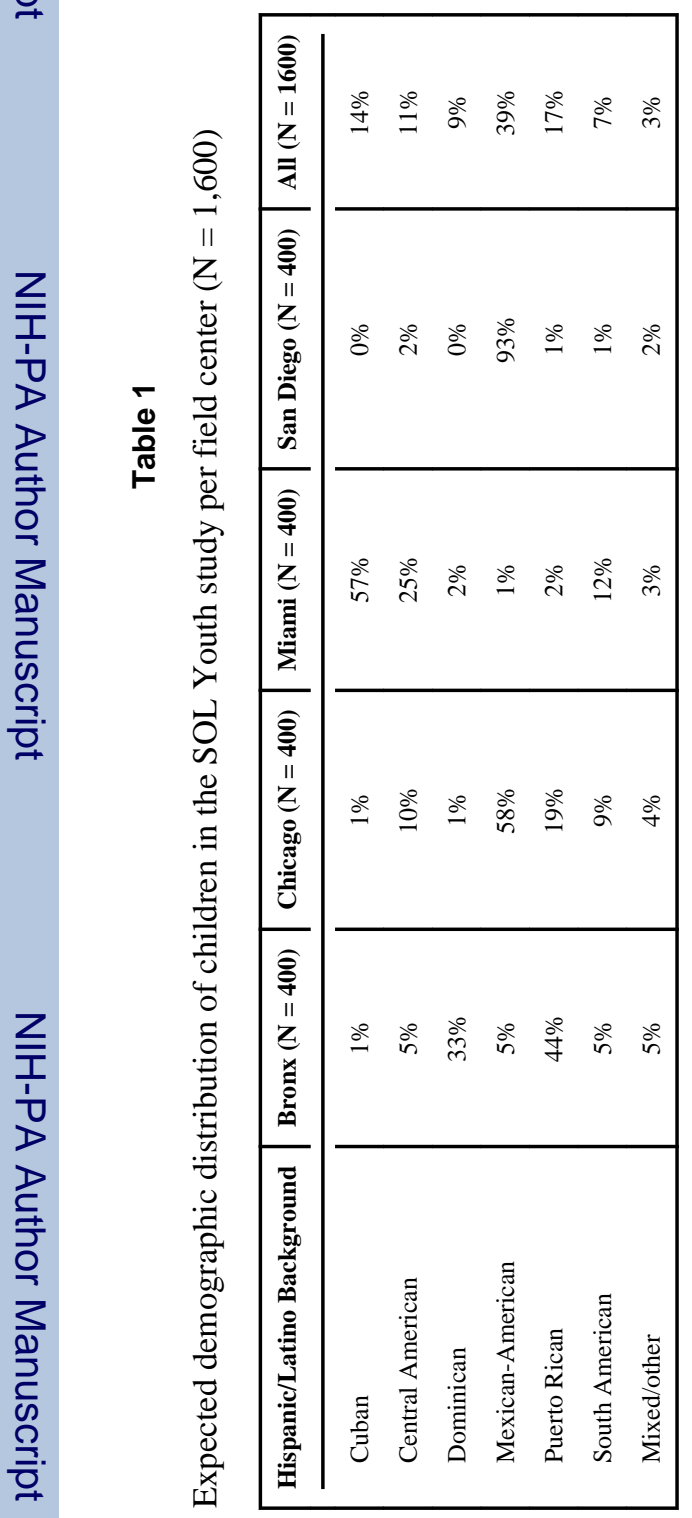

Ann Epidemiol. Author manuscript; available in PMC 2015 January 01. 
Table 2

Measurements and Core Components (C) included in the SOL Youth Exam

\begin{tabular}{|c|c|c|c|}
\hline Measures & Child & Parent (New) & Parent (from HCHS/SOL) $)^{34}$ \\
\hline \multirow{3}{*}{$\begin{array}{l}\text { Demographic, Socio- } \\
\text { Economic, and Health } \\
\text { insurance status }(C)\end{array}$} & $\begin{array}{l}\text { Birth date, sex, race/ethnicity, Latino } \\
\text { background }\end{array}$ & Household composition & Birth date, sex, Latino background \\
\hline & Grade in school & Child's health insurance ${ }^{35}$ & $\begin{array}{l}\text { Income, education attainment, } \\
\text { occupation }\end{array}$ \\
\hline & Employment (adolescents) $^{35}$ & & Educational attainment \\
\hline \multirow[t]{3}{*}{ Anthropometry (C) } & Height, weight & Height, weight & Height, weight \\
\hline & Waist and hip circumferences & Waist and hip circumferences & Waist and hip circumferences \\
\hline & Percent body fat & Percent body fat & Percent body fat \\
\hline \multirow[t]{3}{*}{ Laboratory (C) } & $\begin{array}{l}\text { Lipid panel (total, HDL-C, triglycerides, } \\
\text { LDL-C) }\end{array}$ & & Lipid panel \\
\hline & Fasting glucose, insulin and $\mathrm{HbA1C}$ & & $\begin{array}{l}\text { Fasting glucose, insulin and } \\
\text { HbA1C }\end{array}$ \\
\hline & CRP and other inflammatory markers & & CRP \\
\hline \multirow[t]{5}{*}{ Lifestyle behaviors } & $\begin{array}{l}\text { 24-hr dietary recalls and dietary supplements } \\
\text { (C): one in person and a second one over the } \\
\text { phone. }\end{array}$ & Family meal patterns ${ }^{36}$ & $\begin{array}{l}\text { 24-hr dietary recalls and dietary } \\
\text { supplements }\end{array}$ \\
\hline & $\begin{array}{l}\text { Away-from-home foods, }{ }^{37} \text { food eating } \\
\text { practices with } \mathrm{TV}^{36}\end{array}$ & Food purchasing ${ }^{38}$ & Away-from-home foods \\
\hline & $\begin{array}{l}\text { Smoking and alcohol status and } \\
\text { susceptibility (adolescents) }{ }^{39,40}\end{array}$ & & $\begin{array}{l}\text { Smoking status } \\
\text { Alcohol intake }\end{array}$ \\
\hline & Sleep duration (weekdays and weekends) $)^{41}$ & & Sleep duration and quality \\
\hline & $\begin{array}{l}\text { 7-day accelerometry, physical activity }{ }^{42} \\
\text { questionnaire }{ }^{43}(\mathrm{C})\end{array}$ & & $\begin{array}{l}\text { 7-day accelerometry, physical } \\
\text { activity questionnaire }\end{array}$ \\
\hline \multirow[t]{3}{*}{ Examination } & Cardiorespiratory fitness (step test) ${ }^{23}$ & & ECG findings \\
\hline & Blood pressure (seated)(C) & & Blood pressure \\
\hline & Pubertal development questionnaire ${ }^{24}$ & & \\
\hline Acculturation $(\mathbf{C})$ & $\begin{array}{l}\text { Acculturation scales, }{ }^{44,45} \text { place of birth, age } \\
\text { at arrival, years living in the US, ethnic } \\
\text { identity, }{ }^{46} \text { acculturative stress }{ }^{47}\end{array}$ & $\begin{array}{l}\text { Acculturation scales, }{ }^{44,45} \\
\text { ethnic identity, }{ }^{46} \\
\text { acculturative stress }{ }^{47}\end{array}$ & $\begin{array}{l}\text { Acculturation scale, familisimo, } \\
\text { ethnic identity, discrimination, } \\
\text { language of preference, country of } \\
\text { birth, age at arrival, years living in } \\
\text { the US }\end{array}$ \\
\hline \multirow[t]{3}{*}{$\begin{array}{l}\text { Personal and family } \\
\text { medical history (C) }\end{array}$} & & $\begin{array}{l}\text { Child's general health and } \\
\text { chronic conditions (asthma, } \\
\text { diabetes, hypertension, } \\
\text { hypercholesterolemia, } \\
\text { cancer, attention deficit } \\
\text { disorder) }\end{array}$ & $\begin{array}{l}\text { General health status and chronic } \\
\text { conditions }\end{array}$ \\
\hline & & Child's medication use ${ }^{34}$ & Medication use \\
\hline & & $\begin{array}{l}\text { General health of the child's } \\
1^{\circ} \text { relatives }\end{array}$ & $\begin{array}{l}\text { Family history of CVD in } 1^{\circ} \\
\text { relatives }\end{array}$ \\
\hline $\begin{array}{l}\text { Family and home } \\
\text { environment }\end{array}$ & $\begin{array}{l}\text { Parenting strategies }(\mathrm{C}),{ }^{49} \text { parenting } \\
\text { practices for eating and physical activity } \\
\text { (C) }{ }^{50} \text { dietary and physical activity support } \\
\text { (C), }{ }^{51,52} \text { workout equipment at home, }{ }^{53,54} \\
\text { family functioning (C) })^{55-57}\end{array}$ & $\begin{array}{l}\text { Parenting strategies, }(\mathrm{C}){ }^{49} \\
\text { parenting practices for eating } \\
\text { and physical activity }(\mathrm{C}),{ }^{50} \\
\text { dietary and physical activity } \\
\text { support, }{ }^{51,52} \text { foods in the } \\
\text { home, }{ }^{58} \text { food security, }{ }^{59} \\
\text { family functioning }(\mathrm{C}){ }^{55-57}\end{array}$ & \\
\hline
\end{tabular}




\begin{tabular}{|c|c|c|c|}
\hline Measures & Child & Parent (New) & Parent (from HCHS/SOL) ${ }^{34}$ \\
\hline \multirow{3}{*}{$\begin{array}{l}\text { Mental Health and } \\
\text { body image }\end{array}$} & Depressive symptoms, ${ }^{60}$ anxiety ${ }^{61}(\mathrm{C})$ & & Depressive symptoms, anxiety \\
\hline & $\begin{array}{l}\text { Disordered eating, }{ }^{62} \text { body image, }{ }^{62} \text { social } \\
\text { attitudes towards weight }{ }^{63}\end{array}$ & & \\
\hline & $\begin{array}{l}\text { Social support for healthy eating and } \\
\text { physical activity }{ }^{64}\end{array}$ & & \\
\hline $\begin{array}{l}\text { School and } \\
\text { neighborhood } \\
\text { environment }\end{array}$ & $\begin{array}{l}\text { School food environment, }{ }^{65} \text { after-school } \\
\text { environment }{ }^{66}\end{array}$ & $\begin{array}{l}\text { School type, }{ }^{35} \text { neighborhood } \\
\text { SES, }{ }^{67} \text { food and physical } \\
\text { activity environment, }{ }^{68} \\
\text { barriers to activity in } \\
\text { neighborhood }\end{array}$ & \\
\hline
\end{tabular}


Table 3

Components of the SOL Youth Examination

\begin{tabular}{|c|c|c|}
\hline & Child & Parent/guardian \\
\hline Exam Component & Average time (min) & Average time (min) \\
\hline Fasting Block (children, adults are not fasting) & 60 & 40 \\
\hline Reception \& informed consent/assent process. & 25 & 25 \\
\hline Anthropometry & 10 & 10 \\
\hline Seated Blood Pressure & 15 & - \\
\hline Phlebotomy & 05 & - \\
\hline Snack & 05 & 05 \\
\hline Procedures, flexible sequence & 55 & 10 \\
\hline Fitness Step Test & 10 & - \\
\hline 24-hr dietary recall, supplements & 45 & $10^{*}$ \\
\hline Interviews, flexible sequence (with breaks) & 80 & 80 \\
\hline Child Medical history & - & 5 \\
\hline Child Medications & - & 5 \\
\hline Visit Termination & 20 & 30 \\
\hline Exit interview \& Incentive & 10 & 10 \\
\hline Feedback report (BMI, blood pressure, depressive symptoms) ${ }^{* *}$ & - & 10 \\
\hline Activity monitoring instructions & 10 & 10 \\
\hline
\end{tabular}

* Confirms child responses if needed

$* *$

A second feedback report is later mailed to parents listing laboratory values and interpretation 


\section{Table 4}

Components of the SOL Youth laboratory assessment

\begin{tabular}{|l|l|}
\hline $\begin{array}{l}\text { Glucose and insulin-related metabolic } \\
\text { parameters }\end{array}$ & Fasting glucose, fasting insulin, hemoglobin A1C \\
\hline Lipid profile & Total cholesterol, LDL-cholesterol, HDL- cholesterol, triglycerides \\
\hline $\begin{array}{l}\text { Markers of inflammation, endothelial function } \\
\text { and obesity-related cytokines }\end{array}$ & $\begin{array}{l}\text { von Willebrand factor (vWF) and e-selectin; high sensitive C reactive protein; adiponectin, } \\
\text { interleukin-6, Plasminogen activator inhibitor, tumor necrosis factor-alpha }\end{array}$ \\
\hline Stored specimens & Multiple aliquots of frozen serum, plasma, and packed cells for DNA \\
\hline
\end{tabular}

